Vol. 5, No. 1, 2019

\author{
Karam Shixaliyev $^{1}$, Ibrahim Abbasov ${ }^{2}$, Khaver Sadig ${ }^{3}$ \\ ${ }^{1}$ Department of Organic Substances and Technologies of High Molecular Connections, Azerbaijan State Oil and \\ Industry University, Baku AZ1010, Azerbaijan, 20 Azadlig Avenue, E-mail: kerem_shixaliyev@mail.ru \\ ${ }^{2}$ Department of Physics, Azerbaijan State Oil and Industry University, Baku AZ1010, Azerbaijan, 20 Azadlig \\ Avenue, E-mail: ibrahimabbasov179@gmail.com \\ ${ }^{3}$ Department of Physics, Azerbaijan State Oil and Industry University, Baku AZ1010, Azerbaijan, 20 Azadlig \\ Avenue, E-mail: sadig.xaver@gmail.com
}

\title{
RHEOLOGICAL PROPERTIES OF MELTS AND X-RAY METHOD OF STUDY OF CROSS-LINKED POLYETHYLENE
}

Received: May 02, 2019 / Revised: June 20, 2019 / Accepted: June 26, 2019

(C) Shixaliyev K., Abbasov I., Sadig Kh., 2019

Abstract. In the paper, the X-ray study of cross-linked polyethylene with isopropenyl styrene or acrylonitrile was carried out. It is shown that cross-linking leads to a significant decrease in the area of the exothermic peak, an increase in the resistance of the structured system to thermal oxidation. These data confirm that the increase in resistance to thermal aging of polyethylene crosslinked with acrylonitrile or isopropenyl styrene fraction.

Keywords: chemical bonds, polyethylene, vinyl monomer, IR spectroscopy, methylene groups, modification.

\section{Introduction}

Polyethylene is the cheapest polymer, which occupies the first place in the world polyolefin production. This unique material combines the most valuable properties and the ability to be processed by all high-performance methods that exist for thermoplastics.

Polyethylene is a plastic compound having good dielectric properties, increased shock resistance, low absorption capacity. It does not break, has a low gas and vapor permeability, physiologically neutral, odorless. Polyethylene is not susceptible to alkalis of any concentration, any salt solutions, carbonic, hydrofluoric and concentrated hydrochloric acids. Resistant to oil, vegetable juices, alcohol, water, gasoline. Destroyed by nitric acid, gaseous and liquid fluorine and chlorine. It does not dissolve, but only slightly swells in organic solvents. Resistant to vacuum heating, but collapses in air when heated at $353 \mathrm{~K}$ [1]-[12].

Polyethylene is frost-resistant (up to $333 \mathrm{~K}$ ). Under the action of ultraviolet rays is subjected to photodestruction. It can be easily modified. Additional chlorination, sulfonation, bromination or fluoridation give polyethylene rubber-like properties, improve chemical and thermal resistance. Copolymerization with other polyolefins or polar monomers increases its transparency, elasticity, adhesion characteristics, as well as stress cracking resistance. Mixing polyethylene with different types of polymeric materials improves its other physical properties. Polyethylene is harmless to humans, substances that are hazardous to their health are not released from it [13]-[22].

\section{Experimental Results}

The rheological properties of polyethylene in a fluid state provide considerable information on the mechanical properties and processing behavior of polyethylene, which are necessary for calculating the manufacturing process and processing equipment, as well as at the establishment the optimum product performance. The most important characteristic of polyethylene is the melt viscosity.

In the research of the rheological properties of polymers are widely known the works of G. V. Vinogradov, G. M. Bartenev, E. E. Glukhov and others. In these works, a number of regularities 


\section{Karam Shixaliyev, Ibrahim Abbasov, Khaver Sadig}

were established, in particular for high and low density polyethylene. These results are published in papers [1]-[5].

As for medium-density polyethylene (MDPE), the rheological characteristics of this polymer are studied extremely insufficiently. Taking into account the specific features of the MDPE macrostructure, then the study of the rheological properties of these polyethylenes acquires the substantive necessity.

Thus, the rheological study of MDPE is necessary not only to establish its various grades of flow, but also penetrate to the macrocosm to assess the internal forces acting in various bodies. Under the flow of the polymer imply the necessary shear deformation arising under the action of an external force [23]-[24]. Internal forces, i.e. the resistance to deformation forces, by counteracting external forces, determine the presence of an internal flow. And viscosity is nothing more than a measure of resistance, or the ratio of the shear stress to shear rate. Thus, under the effective viscosity of polyethylene understand [9], [11], [16]:

$$
\eta=\frac{\tau}{\gamma},
$$

where $\eta$-is the share stress (dynes/ $\left.\mathrm{cm}^{2}\right) ; \tau$ - is the shear rate $\left(\mathrm{s}^{-1}\right) ; \gamma-$ is the viscosity (poise).

Polymer melts during flow are characterized by the following features: have high viscosity up to 6 poise or more; many of them exhibit pronounced anomalous properties, i.e. their flow does not obey Newton's law

$$
\tau=\eta \cdot \gamma,
$$

according to which viscosity is the coefficient of proportionality between the applied shear stress $\tau$ and the developing value of shear rate $\gamma$. Practically, the viscosity anomaly of polymers and is expressed in the fact that the values of $\eta$, measured at different $\tau$ and $\gamma$ are different - with increasing $\tau, \eta$ of polymers decreases. The non-Newtonian behavior of melts is due to the peculiarities of supramolecular structures [15] (intermolecular interaction), as well as by the structure of macromolecules (chain character) [1], as a result, during the flow, the reversible structure destroying process and subsequential orientation of macromolecules develop, which lead to a steady fall [7]. The reversible process destruction of the supramolecular structures during the flow of thermoplastics is not accompanied by the destruction of molecules and can be repeated many times with high reproducibility. Such reversible changes occur at the moment of transition from highly elastic strain to steady flow under the condition of more or less significant $\gamma$ [25]. With the flow of high molecular weight polymers, the heat of activation for the viscous flow process

$$
\begin{gathered}
E=R \cdot(I n \cdot \eta) \\
d\left(\frac{1}{T}\right)
\end{gathered}
$$

does not depend on the degree of polymerization, indicating the independence of the elementary act of transfer in the flow process from the chain length of the macromolecule [26]-[28]. Therefore, only a small part of the macromolecule, the segment, participates in the elementary act of transfer. But nevertheless viscosity of polymer bodies depends on the total length of the macromolecule. This dependence is conditioned by the fact that to move a large molecule, as a result of the independent movements of its segments, is needed that the center of gravity of the entire macromolecule move. Furthermore, the viscosity significantly depends on the supramolecular structure of the polymers melt flow.

The region of abnormal viscous flow is a permanent destruction of the supramolecular structure of the polymer, however, this region stretches in velocity and share stress by many decimal orders in the region of the completely destroyed structure (the lowest Newtonian viscosity cannot be achieved in the case of polymer melts).

In the works [1], [3], [5] established the temperature-invariant viscosity characteristic and its universality for a large number of polymers. This characteristic is the dependence of $\eta / \eta$ on $\eta \cdot \gamma$. 


\section{Rheological Properties of Melts and X-Ray Method of Study of Cross-Linked Polyethylene}

\section{Rheological results}

To obtain the true results of rheological studies and to obtain invariant with respect to capillaries geometric dimensions, we measured the rheological parameters of medium-density polyethylene samples at different ratios of length of the diameter $(D, \mathrm{~mm})$ of the capillary. These data, calculated on the dependence of the shear rate $\gamma$ on the shear stress $\tau$, are shown in Fig.1. The values $L / D$ used capillaries are given in Table 1.

Table 1

The rheological parameters of medium-density polyethylene samples

\begin{tabular}{|c|c|c|c|c|}
\hline Experiment No & $M F I(\mathrm{~g} / 10 \mathrm{~min})$ & $L(\mathrm{~mm})$ & $D(\mathrm{~mm})$ & $L / D$ \\
\hline 1 & & 8 & & 6,8 \\
2 & 7 & 16 & $1,18 \pm 0,015$ & 28,7 \\
3 & & 48 & & 38,0 \\
\hline 1 & & & $2,90 \pm 0,005$ & 5,5 \\
2 & 3,9 & 17 & $2,090 \pm 0,015$ & 7,8 \\
3 & & & $1,190 \pm 0,015$ & 13,6 \\
4 & & 7 & $1,00 \pm 0,025$ & 17,34 \\
\hline 1 & 1,4 & 21 & $1,19 \pm 0,015$ & 5,9 \\
2 & & 43 & $1,29 \pm 0,0191$ & 27,4 \\
3 & & & \\
\hline
\end{tabular}

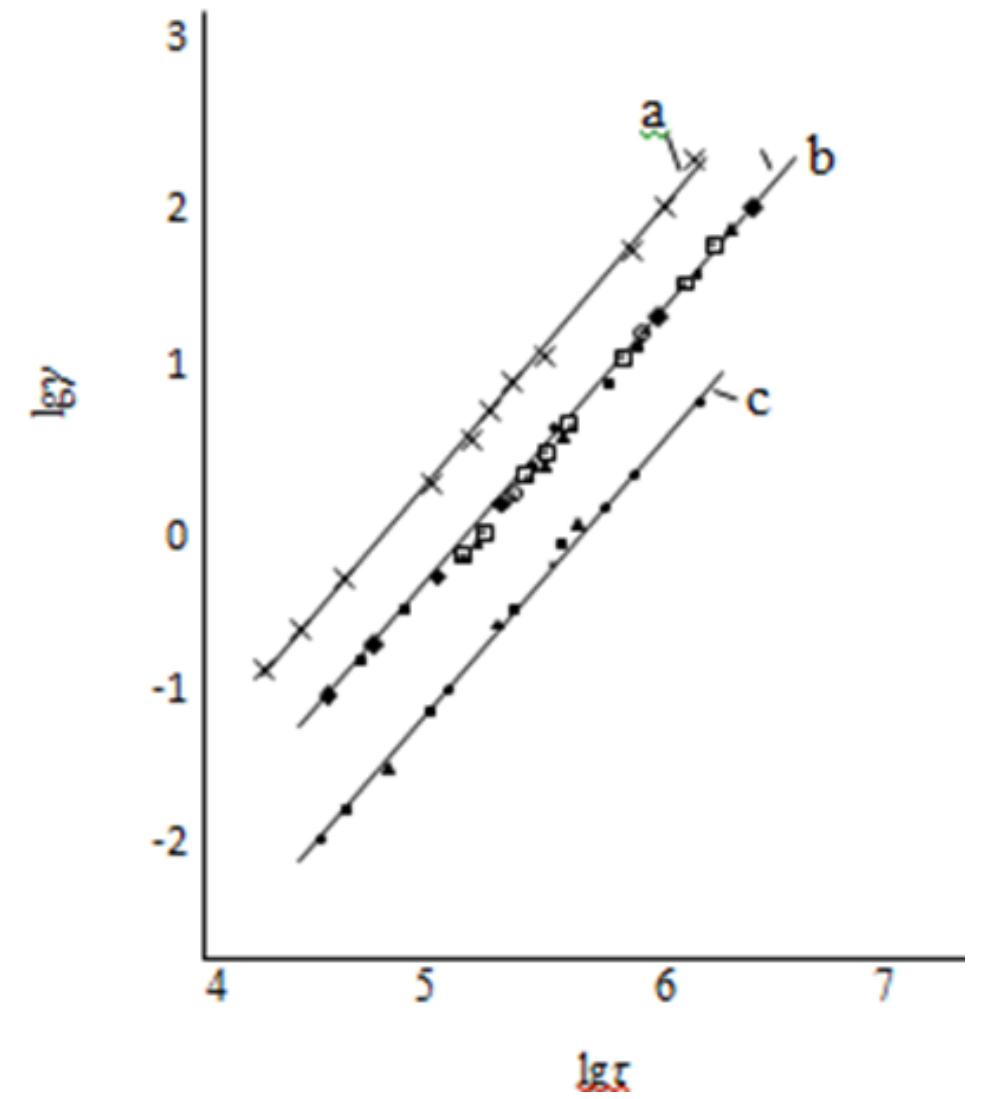

Fig. 1. Rheological flow curves of three grades of HDPE at temperature of $463 \mathrm{~K}^{\wedge}$

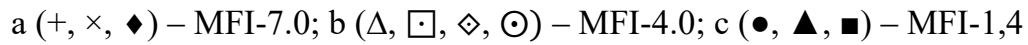

(the data obtained on the capillaries with different designations of $L / D$ is given in Table 1 )

The location of the flow curve is determined only by the brand of the homopolymer or by the magnitude of the MFI. The smaller the MFI, the larger the shear stress polymer flows. This pattern is 


\section{Karam Shixaliyev, Ibrahim Abbasov, Khaver Sadig}

observed in a wide temperature range $408-573 \mathrm{~K}$. The characteristic dependence of the share rate on the shear stress in the temperature range from 408 to $573 \mathrm{~K}$ for three grades of HDPE is shown in Fig. 2. The specific pressure, under the action of which the extrusion of the polymer melt through the capillary was carried out, was changed from 1 to $63 \mathrm{kgf} / \mathrm{cm}^{2}$. Flow curves for HDPE with an MFI equal to 1,4; 4,0; 7,0 are presented in Fig. 2. It is evident that there is a certain temperature range inside which all the experimental data obtained in a fairly wide range of temperatures are located. For HDPE with MFI $=4.0$, this area encompasses $433-513 \mathrm{~K}$. The same areas were established for HDPE with MFI =1,4 and 7,0. They were equal to $443-523 \mathrm{~K}$ and $433-523 \mathrm{~K}$, respectively. In these temperature ranges effective viscosity vary slightly with temperature.
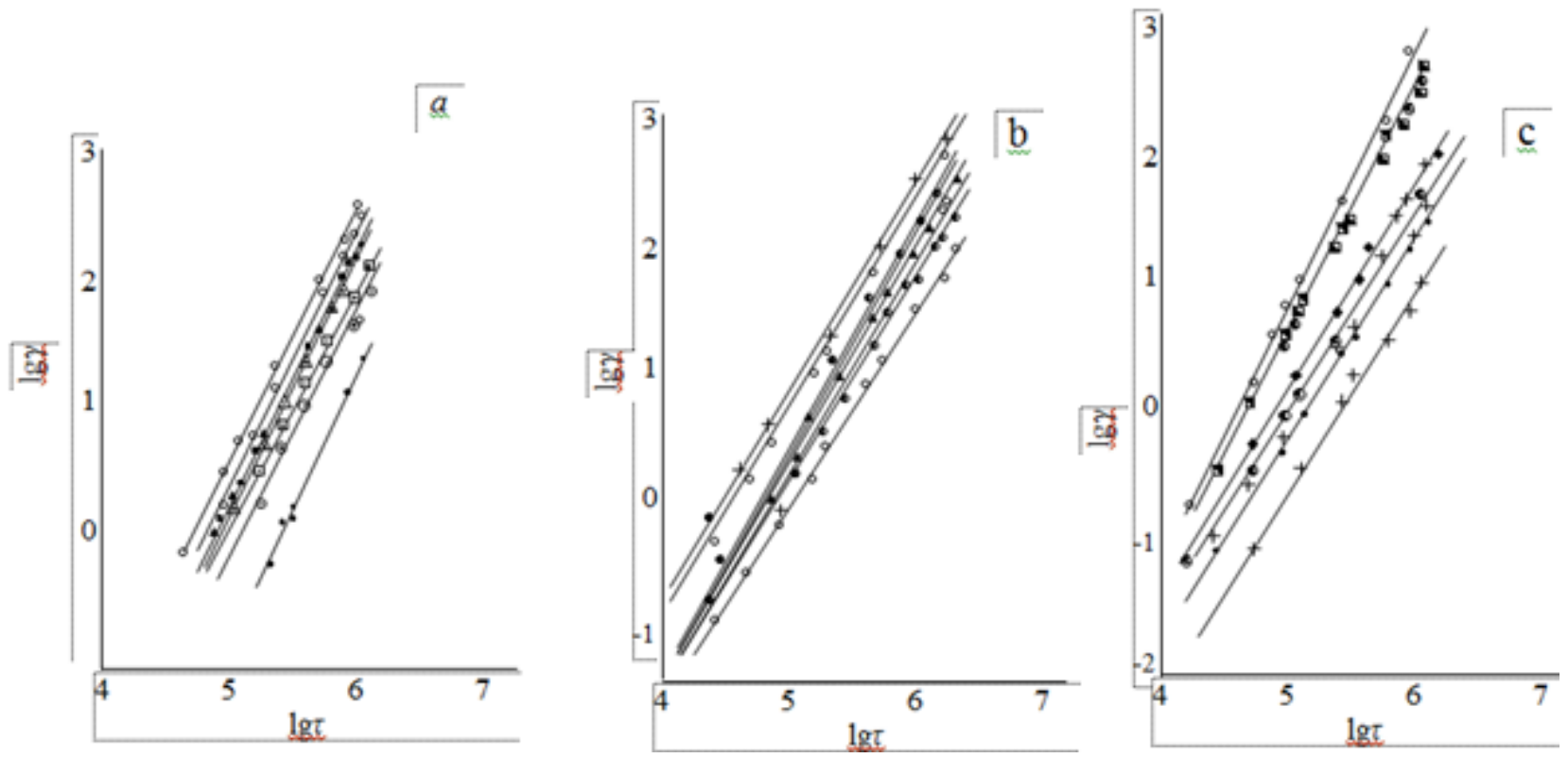

Fig. 2. Rheological flow curves of three grades of HDPE at different temperatures

Another characteristic property of the HDPE melt flow is the subordination of the ratio $(\tau . \gamma)$ to the flow of power law over the entire temperature range considered.

To consider the temperature dependence of the melt viscosity of HDPE, the experimental data obtained were processed in accordance with the accepted method [4] and provided as a dependency $\lg \eta$ on $\tau$, where $\eta=\tau / \gamma$. In Fig. 3 (a, b, c) these dependences are given for HDPE samples with the magnitude of the MFI $=1.4,4.0$, and 7.0, respectively.
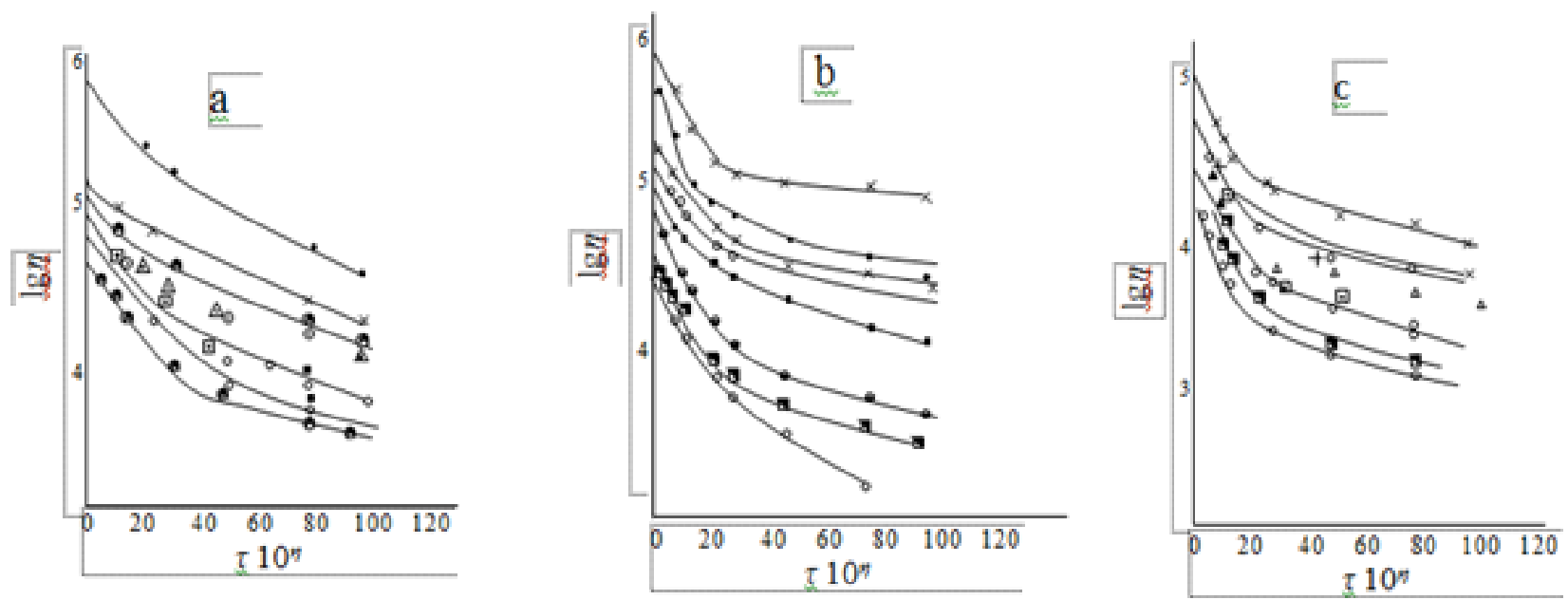

Fig. 3. Dependence of effective viscosity of melt grades on shear stress at various temperatures 


\section{Rheological Properties of Melts and X-Ray Method of Study of Cross-Linked Polyethylene}

Using the method of determining the value of the melt viscosity, published in studies [12]-[24], the highest melt viscosity values of three HDPE samples were calculated in a wide temperature range. The results showed (Fig. 4) that for HDPE there are three temperature ranges, each of which is characterized by certain values of apparent heat of activation for viscous flow $\Delta \mathrm{H}$.

Dependence of $\Delta \mathrm{H}$ on temperature for three HDPE is represented in Fig. 5. The figure shows that in the temperature range $408-433 \mathrm{~K}$ in the values of $\Delta \mathrm{H}$ for the specified polyethylene samples, there is a sharp decrease in $\Delta \mathrm{H}$.

The latter effect may be due to the destruction of ordered regions in the polyethylene melt, therefore at $428-433 \mathrm{~K}$ occurs the transition of the structure of the melt polyethylene to a new state in which the sizes of the kinetic units are such that the value of heat of activation equal to $0.6-0.7 \mathrm{kcal} / \mathrm{mole}$ is already sufficient to move them under the action of thermal motion.

At temperatures above $523 \mathrm{~K}$, melt viscosity of the HDPE begins to decrease sharply, which is obviously associated with the onset of the process of its intense thermal destruction. The accompanying process of the destruction of macromolecules leads to an increase in the amount of the apparent heat of activation for viscous flow. Thus, apparently, a significant part of the thermal energy supplied to the initial polymer is expended mainly on the thermal oxidative destruction of macromolecules. Accordingly, the value $\Delta \mathrm{H}$ in the temperature range above $523 \mathrm{~K}$, should be presented as the total activation heat of two main and simultaneously occurring processes of viscous flow and thermaloxidative destruction per mole of chain segments.

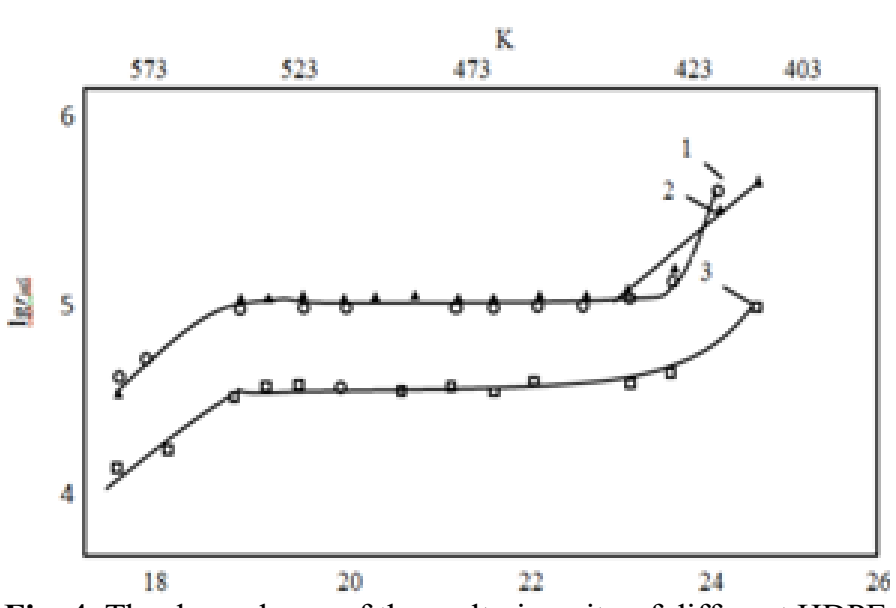

Fig. 4. The dependence of the melt viscosity of different HDPE grades on temperature: 1 - MFI-1.4; 2 - MFI-4.0; 3 - MFI-7.0

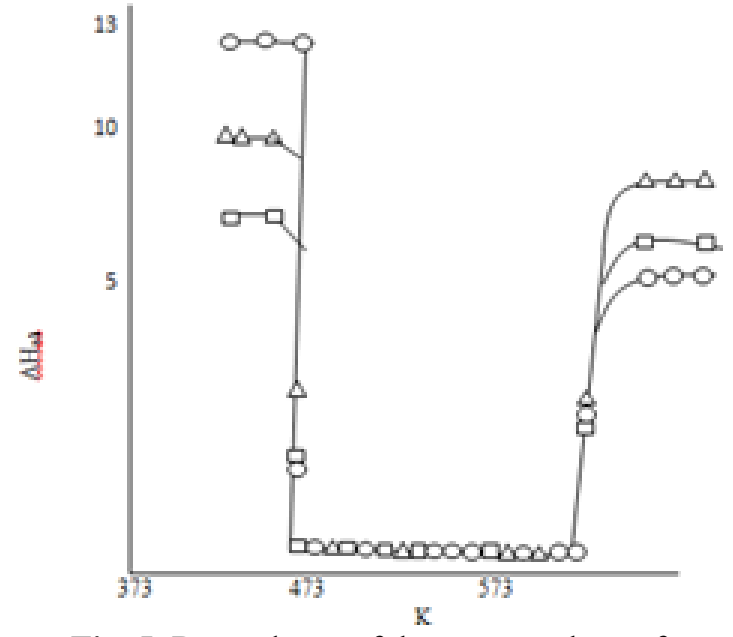

Fig. 5. Dependence of the apparent heat of activation for viscous flow $\left(\Delta H^{*}\right)$ of different

HDPE grades on temperature: 1 - MFI-1.2; 2 - MFI-4.0; 3 - MFI-7.0

A generalized representation of the viscosity properties of polymer melts in $\eta / \eta$ o - $\gamma \cdot \eta$ o coordinates is particularly important for base samples. A generalized characteristic of HDPE samples is illustrated in Fig. 6. Here, two solid lines indicate the allowable universal scope of the temperature-invariant viscosity characteristic of linear polymer melts. The dots 1 and 2 (Fig. 6) are experimental data for three samples of HDPE in the temperature range 408-573 K.

\section{X-ray study of polyethylene cross-linked with different content of isopropenyl-styrene fraction}

As illustrated in Fig. 5 the generalized dependency describes quite satisfactorily the flow of HDPE.

At present, radiographic determination of the degree of crystallinity of polyolefins is widely used [1], [2].

The issue of availability of a chemical bond between polyethylene and vinyl monomers was clarified by IR spectroscopy, X-ray diffraction and differential thermal analyzes [11], [24]-[28]. 


\section{Karam Shixaliyev, Ibrahim Abbasov, Khaver Sadig}

By the method of X-ray structural analysis it was determined that in the modified polyethylene the crystal structure is preserved (Fig. 6). However, with an increase in the degree of cross-linking, there is a slight decrease in the degree of crystallinity [5].

The decrease in the degree of crystallinity is caused by the appearance of cross-links between the molecules of polyethylene and vinyl monomer and as the degree of hardening of polyethylene increases, a decrease in the degree of crystallinity of the polymer is observed [8].

With increasing of styrene content in the composition, the amount of chemically unbound polystyrene increases and polyethylene decreases [10]. When constructing a graphical dependence of the content of free polyethylene and polystyrene on the initial amount of styrene in the composition, the best indicators of structured polyethylene fall on the content of unbound polyethylene and polystyrene in it within $4 \%$ [7]. These conditions are achieved at an initial weight ratio of polyethylene and styrene in the composition of 1:0.45 and at the highest yield of the insoluble fraction of the cross-linked polyethylene (94\%). X-ray diffraction analysis data are in good agreement with the results of differential thermal analysis.

\section{Results of differential thermal and thermogravimetric analysis}

Fig. 7 provides the curves of differential thermal and thermogravimetric analyzes, showing that the area of the endothermic peak, which characterizes the softening temperature of cross-linked polyethylene, is slightly less than for the initial polyethylene. This fact testifies a decrease in the degree of crystallinity (8-10\%) of structured polyethylene, which is characteristic of cross-linked polymers.

The taken thermograms not only confirm the facts of changes in the degree of crystallinity of polyethylene during cross-linking, they show the thermal effects of softening and oxidation of samples of the initial and modified polyethylene.

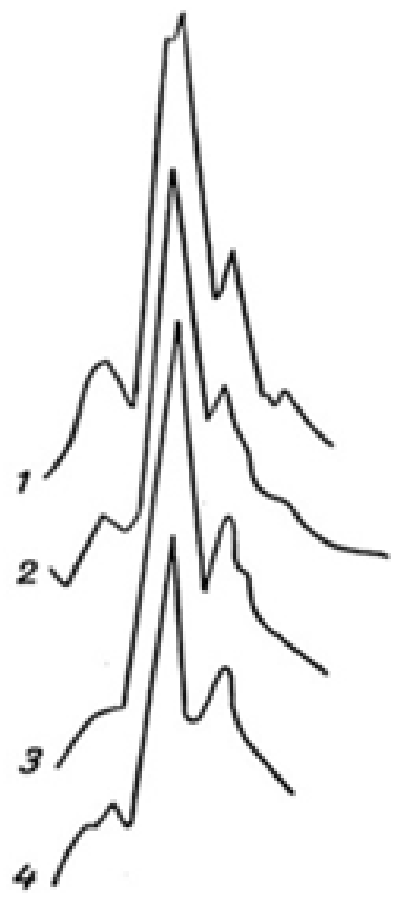

Fig. 6. Radiographs of the initial (1) and polyethylene cross-linked with different content of isopropenyl-styrene fraction $(2,3,4): 2-20$

mass fraction; 3-40 mass fraction; 4-100 mass fraction of the isopropenyl styrene fraction per 100 mass fraction of polyethylene and 1.3 mass fraction of tert-butyl peroxide

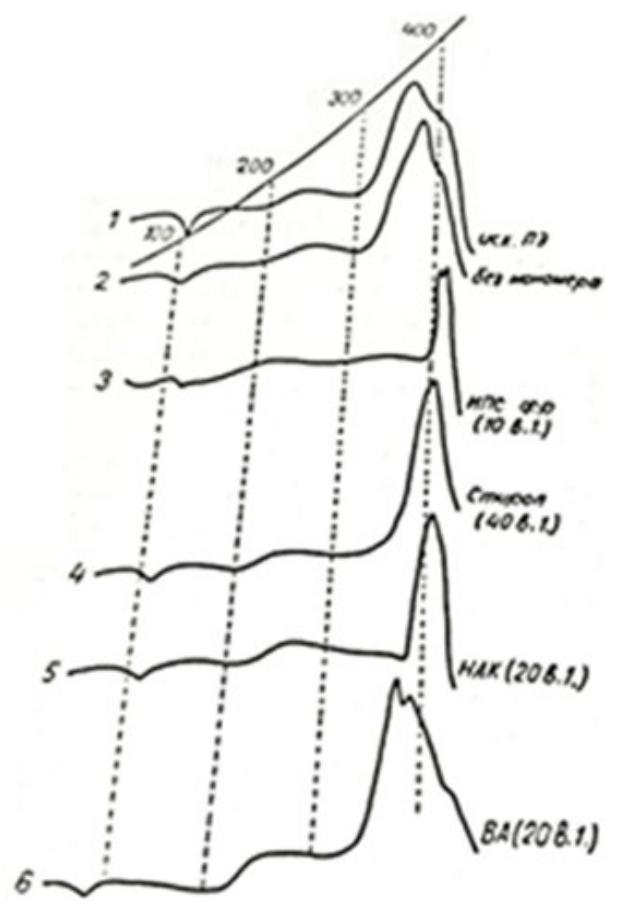

Fig. 7. DTA curves of polyethylene crosslinked with various vinyl monomers

The normal melting peak, characteristic of non-crosslinked high-density polyethylene, appears at a temperature of 378-381 K (Fig. 7, curve 1). The positions of the melting peaks on the thermograms of 


\section{Rheological Properties of Melts and X-Ray Method of Study of Cross-Linked Polyethylene}

cross-linked polyethylene (Fig. 7, curves 2-6) are practically unchanged. The latter is consistent with the literature data.

The thermograms shown in Fig. 7 indicate that the cross-linking of polyethylene with vinyl monomers increases the resistance of the polymer system to thermal oxidation according to the nature of the monomer.

The analysis of thermograms (Fig. 7) shows that when cross-linking polyethylene with vinyl acetate or in the presence of only an organic peroxide, there is a slight increase in the oxidation temperature of the polymer from $623 \mathrm{~K}$ for the initial polyethylene (curve 1) up to $648 \mathrm{~K}$ for the above systems (curves 2, 6). The decrease in sample weight at the oxidation temperature is $38 \%$ for the initial polyethylene (curve 1), and for polyethylene cross-linked with vinyl acetate or only an organic peroxide $36.4 \%$ (curve 5) and $46.7 \%$ (curve 2), respectively.

Cross-linking of polyethylene with acrylonitrile (Fig. 7, curve 5) or with styrene (Fig. 2, curve 4) raises the oxidation temperature of the polymer to $673-683 \mathrm{~K}$. This temperature accounts for $13.6 \%$ (Fig. 7, curve 4) and $23 \%$ (Fig. 2, curve 3) mass loss, respectively.

Structuring polyethylene with isopropenyl styrene fraction shifts the peak of polymer oxidation towards higher temperatures $(683-693 \mathrm{~K})$.

The weight loss of the sample is $12 \%$ of the spatial grid of the polymer, resulting in increased resistance of the polymer to the effects of temperature. Our research showed that in many cases there is no need for complete thermodynamic combination of components in polymer-polymer systems, since the specified properties of the composition are often achieved precisely because the system is incompatible. We have proved this regularity from the standpoint of thermodynamic compatibility, and especially the colloid chemical one represented in disperse systems.

\section{The study of the IR spectrum of non-cross-linked and cross-linked polyethylene}

These studies were conducted with the aim of cross-linking polyethylene with acrylonitrile or styrene. In this case we used the most modern research methods. The issue of the presence of a chemical bond between polyethylene and vinyl monomers was clarified by IR spectroscopy, X-ray diffraction and differential thermal analyzes.

The IR spectra of films with the thickness up to $100 \mu \mathrm{m}$ were recorded using VR spectrometer with $\mathrm{NaCl}$ and $\mathrm{LiF}$ prism in the region $700 \mathrm{~cm}^{-1}$. X-ray analyzes (plate $1.5 \times 2.5 \mathrm{~mm}$ ) were carried out with a URS-50 IM apparatus with ionization registration.

Thermal analysis of samples $(1 \times 2 \mathrm{~mm}$ crumb) was performed on F.Paulik - J.Paulik - L.Erdey derivatograph system in the temperature range $298-6273 \mathrm{~K}$ and the heating rate (degree/min) using platinum crucible.

The presence of a chemical bond between polyethylene molecules of vinyl monomer can be judged by the spectra taken from the extracted samples of the cross-linked polymer (Fig. 8).

In the spectrum of polyethylene cross-linked with styrene (Fig. 9), the appearance of additional absorption bands at $750 ; 840 ; 908 ; 1028 ; 1600-1940 \mathrm{~cm}^{-1}$ should be classified as the methylene groups of the aromatic series. These bands in the spectrum indicate the presence of structures

$\left[-\mathrm{CH}_{2}-\mathrm{CH}-\right.$

$\mathrm{C}_{6} \mathrm{H}_{5} \quad$ in cross-linked polymer.

As it can be seen in Figs. 8-9, in the spectra the band at $730 \mathrm{~cm}^{-1}$, which is usually used to assess the crystalline state of polyethylene in the spectra of cross-linked polyethylene, retains its intensity.

In Fig. 10 in the spectrum of polyethylene cross-linked with isopropenyl styrene fraction, intense absorption bands in region of $886-892 \mathrm{~cm}^{-1}$ belong to the isopropyl group, and the absorption bands in the region of $1600-1900 \mathrm{~cm}^{-1}$ to the methylene groups of the aromatic series.

The study of the spectrogram of polyethylene, cross-linked with acrylonitrile (Fig. 11) shows the appearance of absorption bands in the region $1070 \ldots 2246 \mathrm{~cm}^{-1}$ which are characteristic, respectively 
Karam Shixaliyev, Ibrahim Abbasov, Khaver Sadig

deformation stretching vibrations of $\mathrm{C} \equiv \mathrm{N}$ bonds [2], [4] allowing to continue the presence of groups in structured polyethylene.

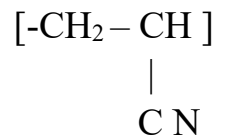

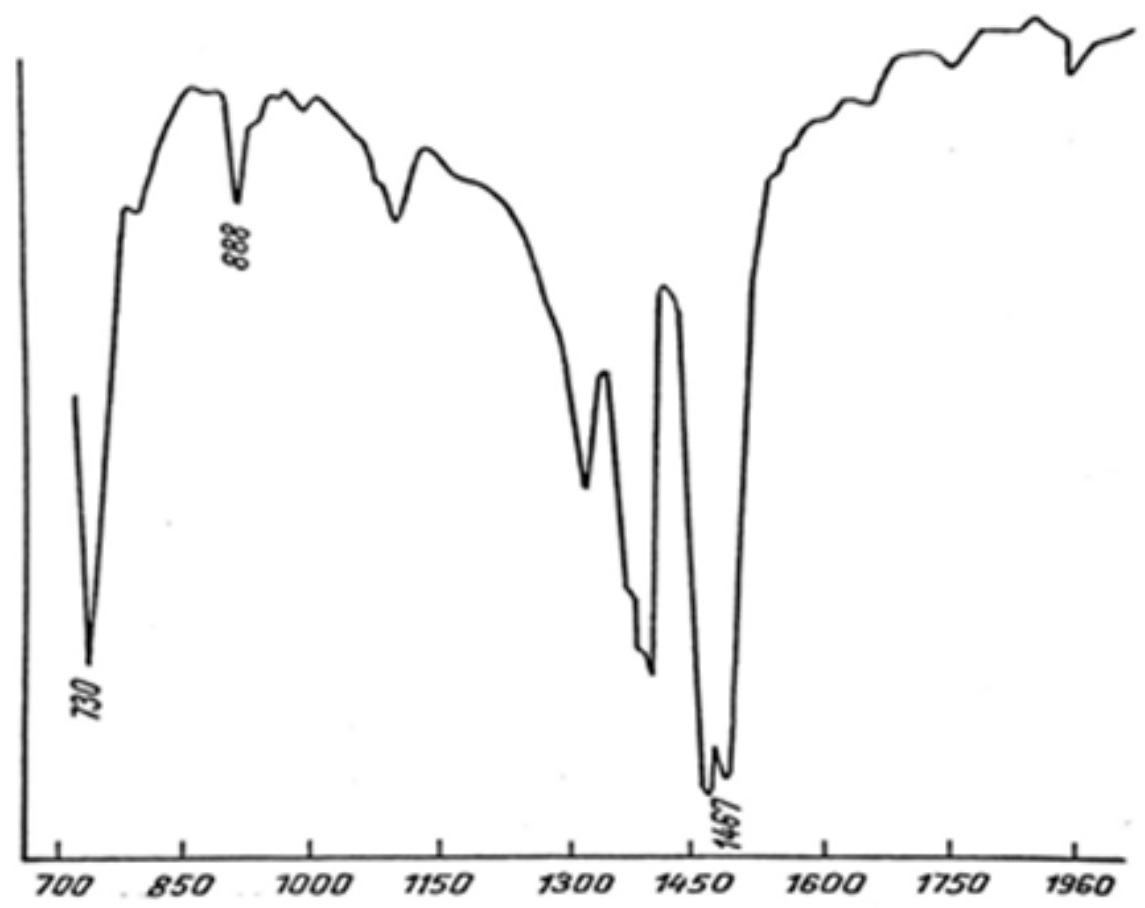

Fig. 8. IR spectra of non-cross-linked polyethylene

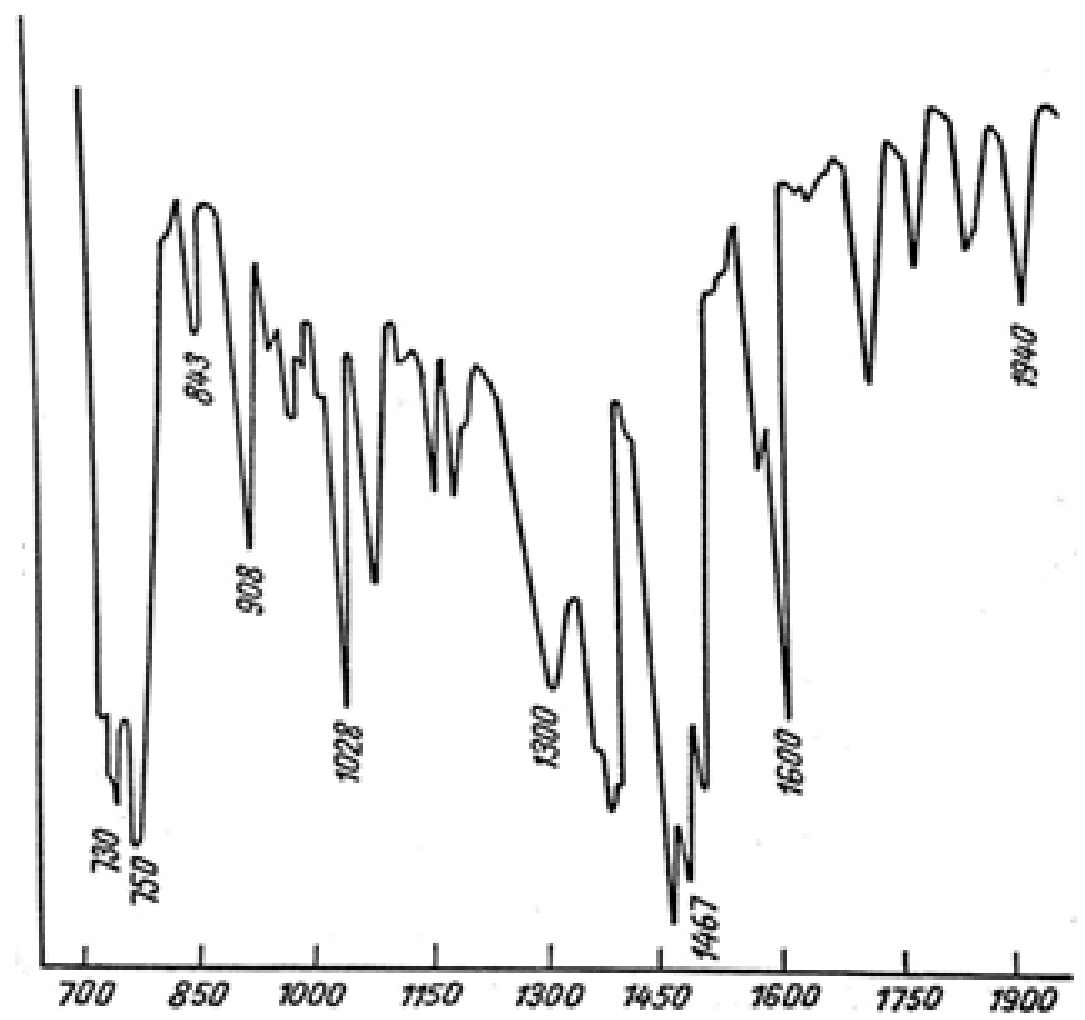

Fig. 9. IR spectra of polyethylene cross-linked with vinyl monomer fraction. Composition: $\mathrm{PE}-100$ mass fraction, styrene -40 mass fraction, tert-butyl peroxide -1.3 mass fraction 


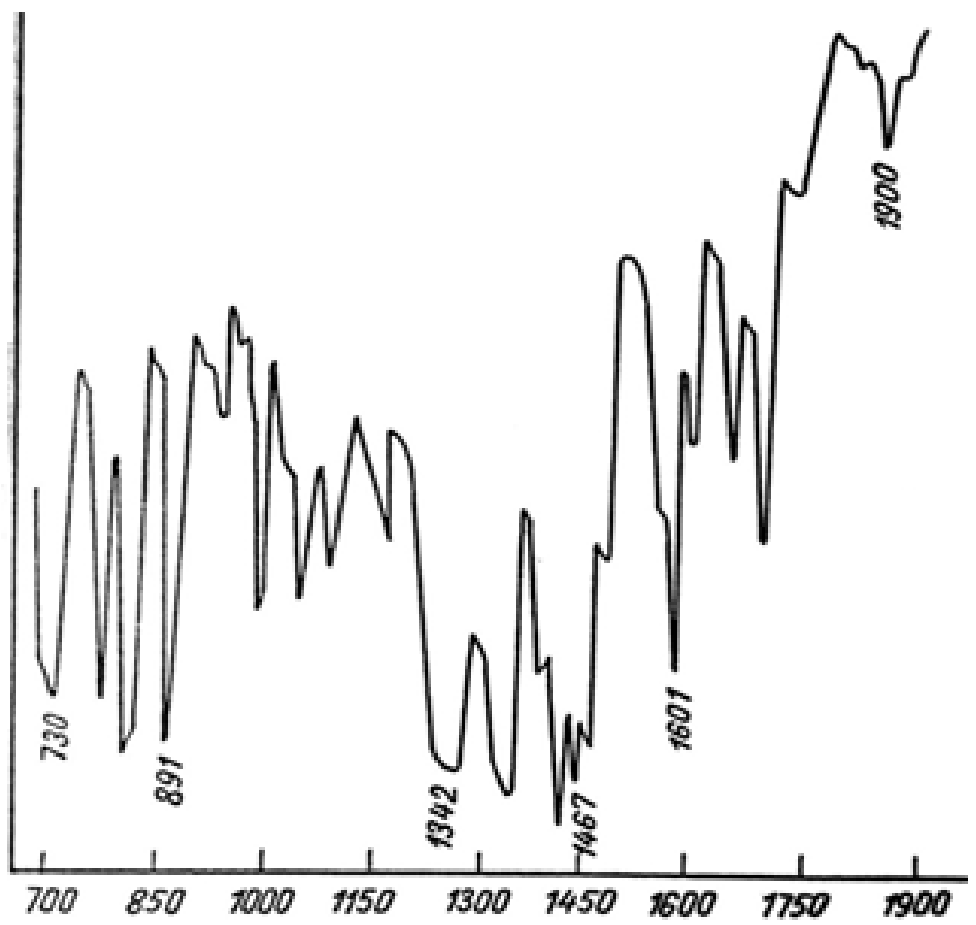

Fig. 10. IR spectra of PE cross-linked with vinyl acetate. Composition: PE - 100 mass fraction, vinyl acetate 20 mass fraction, tert-butyl peroxide -1.3 mass fraction

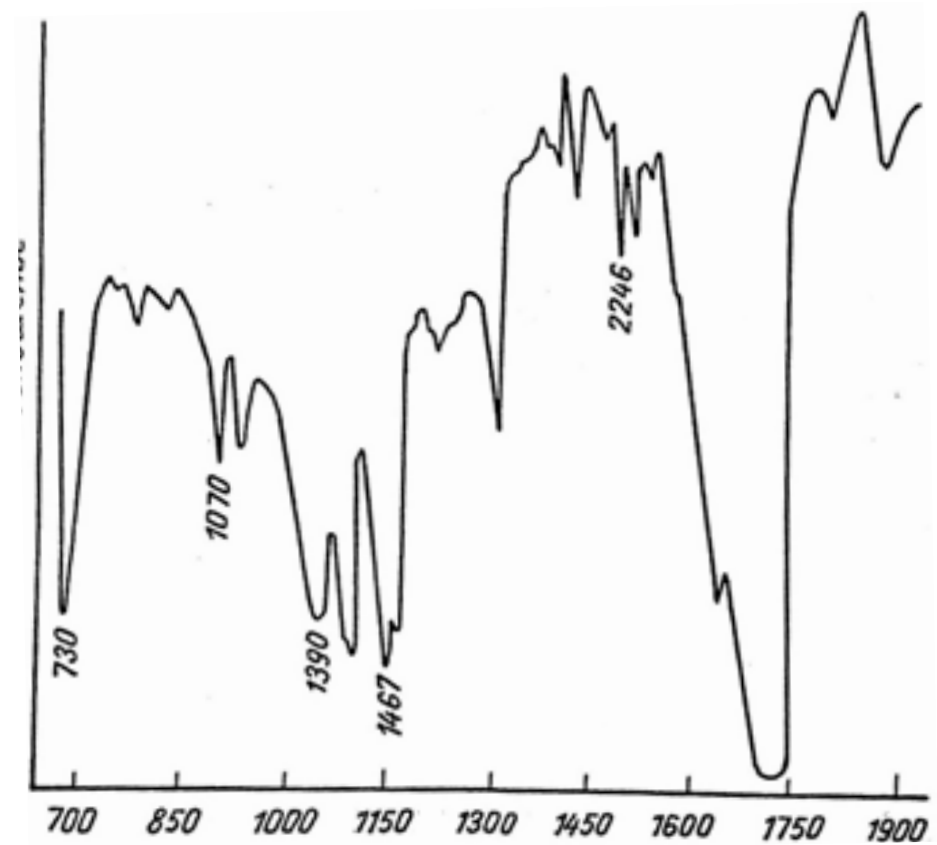

Fig. 11. IR spectra of polyethylene cross-linked with acrylonitrile. Composition: PE - 100 mass fraction, acrylonitrile -20 mass fraction, tert-butyl peroxide -1.3 mass fraction

In the spectrum of polyethylene cross-linked with vinyl acetate (Fig. 12), the appearance of a characteristic absorption band in the region $1720-1730 \mathrm{~cm}^{-1}$ should be attributed to stretching vibrations of the $\mathrm{C}=\mathrm{O}$ containing groups [6]. This allows to suggest that in the process of polyethylene cross-linking occurs cross-linking of structures with the polymer chain.

$$
\begin{gathered}
{\left[-\mathrm{CH}_{2}-\mathrm{CH}-\quad\right]} \\
\mid \\
\text { O-CO- } \mathrm{CH}_{3}
\end{gathered}
$$




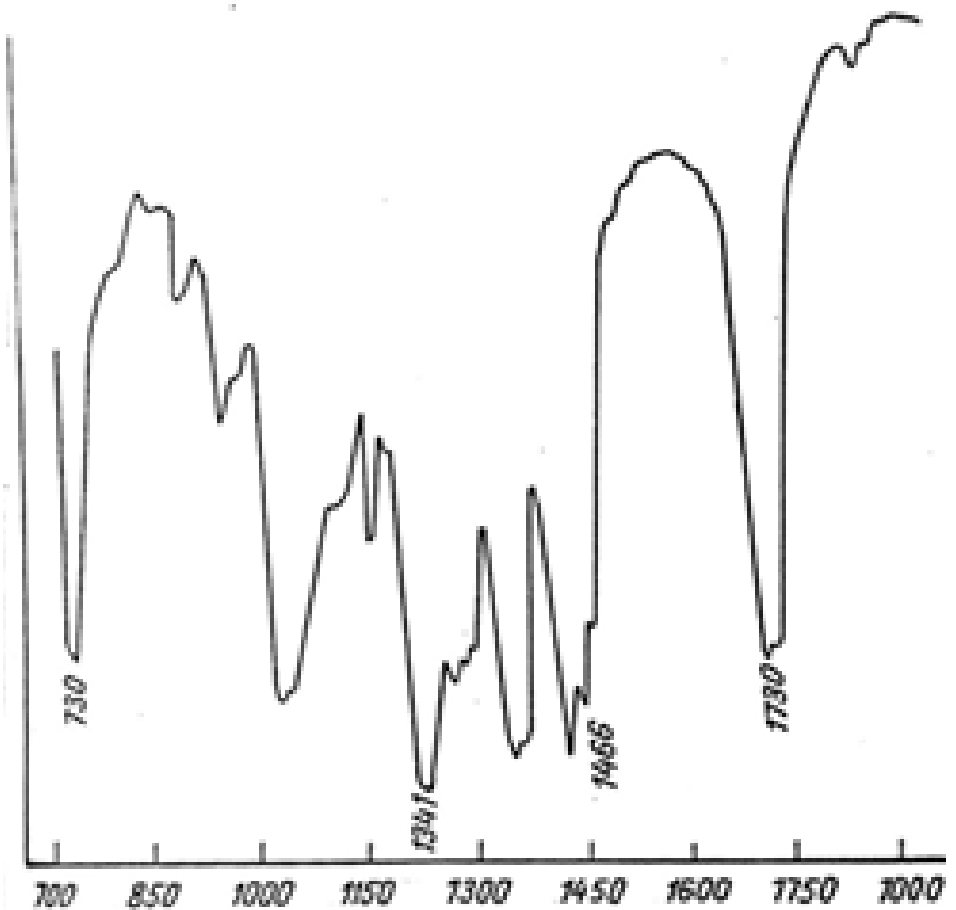

Fig. 12. IR spectra of PE cross-linked with vinyl acetate. Composition: $P E-100$ mass fraction, vinyl acetate -20 mass fraction, tert-butyl peroxide -1.3 mass fraction

The Table 2 indicates the optical density of the characteristic absorption bands of cross-linked polyethylene, depending on the content of monomer composition.

Table 2

The change in the optical density of the characteristic absorption bands of cross-linked polyethylene, depending on the content of monomer composition

\begin{tabular}{|c|c|c|c|c|c|c|c|c|}
\hline \multirow{3}{*}{$\begin{array}{c}\text { Monomer content } \\
\text { in mass fraction per } 100 \text { mass } \\
\text { fraction of polyethylene }\end{array}$} & \multicolumn{8}{|c|}{$\begin{array}{l}\text { Absorption bands in polyethylene cross-linked with monomers at the } \\
\text { respective frequencies: } \mathrm{cm}^{-1}\end{array}$} \\
\hline & \multicolumn{3}{|c|}{ Styrene } & \multicolumn{2}{|c|}{$\begin{array}{l}\text { Isopropenyl } \\
\text { styrene }\end{array}$} & \multicolumn{2}{|c|}{ Acrylonitrile } & $\begin{array}{l}\text { Vinyl } \\
\text { acetate }\end{array}$ \\
\hline & 908 & 1028 & 1600 & 891 & 1600 & 1080 & 2246 & $1720-1730$ \\
\hline 10 & 0,08 & 0,10 & 0,15 & 0,20 & 0,31 & 0,10 & 0,14 & 0,56 \\
\hline 20 & 0,12 & 0,17 & 0,27 & 0,38 & 0,46 & 0,11 & 0,38 & 0,69 \\
\hline 40 & 0,21 & 0,28 & 0,47 & 0,44 & 0,47 & 0,13 & 0,39 & 0,80 \\
\hline 60 & 0,22 & 0,33 & 0,60 & 0,46 & 0,78 & 0,15 & 0,37 & 0,98 \\
\hline 80 & 0,31 & 0,43 & 0,80 & 0,54 & 0,81 & 0,12 & 0,40 & 1,21 \\
\hline
\end{tabular}

\section{Conclusions}

The analysis of the infrared spectra of the cross-linked samples testifies that the interaction between polyethylene macromolecules and vinyl monomers in the presence of tert-butyl peroxide leads to a chemical reaction, resulting in monomeric units chemically bonded to polyethylene losing the ability to dissolve in appropriate solvents and give characteristic absorption bands. These studies were performed in order to crosslink polyethylene with acrylonitrile or styrene. At the same time we used the most modern research methods. In our studies it was determined that in many cases there is no need for a complete thermodynamic combination of components into polymer-polymer systems, since the specified properties of the composition are often achieved precisely because the system is incompatible. We have proved this regularity from the standpoint of thermodynamic compatibility and especially colloid-chemical, 


\section{Rheological Properties of Melts and X-Ray Method of Study of Cross-Linked Polyethylene}

represented in disperse systems. The question of the presence of a chemical bond between polyethylene and vinyl monomers was clarified by IR spectroscopy, X-ray diffraction and differential thermal analysis.

\section{References}

[1] V. S. Anpilogova, V. S. Osipchik, T. P. Kravchenko, and Ts. B. Tsyritorov, "Svoystva nanokompozitov na osnove polietilena visokoy plotnosti" ["Properties of nanocomposites based on high density polyethylene"], Uspekhi $v$ khimii i khimicheskoy tekhnologii [Advances in Chemistry and Chemical Technology], vol. 31, no. 11, pp. 20-22, 2017. [in Russian].

[2] A. E. Prismakova, A. B. Dyagileva, and A. I. Smirnova, "Reologichekiye svoystva sulfatnogo lignina, modifitsirovannogo zol-gel metodom" ["Rheological properties of sulphate lignin modified by sol-gel method"], Lesnoy zhurnal [Forestry journal], no. 3, pp. 137-148, 2018. [in Russian].

[3] N. M. Mukhin, and V. G. Burindin, Opredeleniye reologicheskikh i fiziko-mekhanicheskikh svoystv polimernikh materialov [Determination of rheological and physico-mechanical properties of polymer materials]. Ekaterinburg, Russia: UGLTU, 2018. [in Russian].

[4] N. P. Petrova, N. A. Tarasov, N. F. Ushmarin, M. S. Reznikov, and N. I. Koltsov, "Issledovaniye vliyaniya kombinatsii antipirenov na kinetiku goreniya rezini na osnove butadien-nitrilnogo kauchuka" ["Investigation of influence of fire retardants combinations on combustion kinetics of rubber on base of butadiene-nitrile rubber"], Izvestiya Vysshikh Uchebnykh Zavedenii [News of Higher Education Institutions], vol. 57, no 4, pp. 52-55, 2014. [in Russian].

[5] S. I. Sandalov, etc., "Razrabotka termoagressivostoykoy rezini na osnove butadiene-nitrilnikh kauchukov" ["Development of thermo-aggressive rubber based on nitrile-butadiene rubbers"], Vestnik Kazanskogo tekhnologicheskogo universiteta [Bulletin of Kazan Technological University], vol. 17, no. 3, pp. 108-110, 2014. [in Russian].

[6] V. D. Voronchikhin, E. I. Lesik, K. A. Dubkov, D. P. Ivanov, and S. V. Semikolenov, "Issledovaniye svoystv elastomernikh kompozitsiy na osnove karboksidirovannikh buadien-nitrilnikh kauchukov" ["The study of the properties of elastomeric compositions based on carboxydiene buadiene nitrile rubbers"], in Proc. 11th Int. Scientific and Practical Conf. "Rubber industry. Raw material. Materials. Technology", Moscow, 2014, pp. 56-58. [in Russian].

[7] K. Karadeniz, and N. Ergüller, "Investigation of plasticizer effect of hazelnut oil and its epixidized derivative on chloroprene and nitrile rubbers", Kautsch. Gummi, Kunststoffe, no. 10, pp. 49-54, 2012.

[8] S. A. Mansour, M. A. El-Salam, A. H. Moharram, M. Hussein, and Faisal A. M. Al-Agel "The order addition effect of carbon black/graphite on the electrical properties of rubber composites", Journal of Applied Polymer Science, vol. 126, no. 2, pp. 593-600, 2012.

[9] M. Nofar, A. Maani, H. Sojoudi, M. C. Heuzey, and P. J. Carreau, "Interfacial and rheological properties of PLA / PBAT and PLA / PBSA blends and their morphological stability under shear flow", Journal of Rheology, vol. 59, no. 2, pp. 317-333, 2015.

[10] M. Trifkovic, A. Hedegaard, K. Huston, M. Sheikhzadeh, and C. W. Macosko, "Porous films via PE/PEO cocontinuous blends", Macromolecules, vol. 45, no. 15, pp. 6036-6044, 2012.

[11] E. J. Dil, P. J. Carreau, and B. D. Favis, "Morphology, miscibility and continuity development in poly(lactic acid)/poly(butylene adipate-co-terephthalate) blends", Polymer, vol. 68, pp. 202-212, 2015.

[12] K. S. Shikhaliyev, "Teoriya i praktika proizvodstva kompozisionnikh materialov na osnove polimernikh smesey" ["Theory and practice of the production of composite materials based on polymer blends"], International Center for Scientific Cooperation "Science and education", part 1, pp. 12-18, 2017. [in Russian]. 2017.

[13] K. S. Shikhaliyev, "Compositions based on elastomers", European science review, no. 7-8, pp. 147-150,

[14] I. G. Klimov, E. O.Koval, A. I. Agafonova, Yu. N. Kondratiev, and E. A. Mayer, "Sravneniye vliyaniya ispolzuyemogo proizvodstvennogo protsessa na strukturu i svoystva polietilena nizkoy plotnosti" ["Comparing the influence of the manufacturing process employed on the structure and properties of low-density polyethylene"], International Polymer Science and Technology, vol. 38, no. 11, pp. 21-25, November, 2011. [in Russian].

[15] A. D. Kalashnikov, N. K. Balabaev and E. F. Oleynik, "Strukturnye vozmushcheniya ortorombicheskogo polietilena s $\mathrm{CH} 3$ razvetvleniyami v tsepyakh" ["Structural distortion of the orthorhombic crystal of polyethylene with $\mathrm{CH} 3$ branches in chains"], Vysokomolekulyarnye soedineniya [High Molecular Weight Compounds], ser. A, vol. 47, no. 10, pp. 1767-1781, 2005. [in Russian].

[16] Ye. Koval, Ye. Skvortsevitch, and E. Mayer, "VLDPE synthesis by radical ethylene polymerization in 


\section{Karam Shixaliyev, Ibrahim Abbasov, Khaver Sadig}

tubular reactors - Negative factor or unrealized opportunities", Journal of Materials Science and Chemical Engineering, no. 1, pp. 11-16, 2013.

[17] C. James, and A.Randall, "Review of high resolution liquid 13 carbon nuclear magnetic resonance characterizations of ethylene based polymers", Jms-Rev. Macromol. Chem. Phys., vol. 29, no. 2-3, pp. 297-303, 1989.

[18] Takao Usami, and Shigeru Takayama, "Fine-branching structure in high-pressure, low-density polyethylenes by 50.10-mHz 13C NMR analysis", Macromolecules, vol. 17, no. 9, pp. 1756-1761, 1984.

[19] A. A. Bunyatzade, A. M. Abbasov, "Visokonapolnenniye kompozisionniye materiali na osnove razlichnikh sortov polietilena" ["Highly filled composite materials on the basis of various grades of polyethylene"], “Tsniit Enertekhim”, Sbornik nauchnikh trudov, Moscow, pp. 8-17, 1991. [in Russian].

[20] A. M. Abbasov, "Stabilizatsiya PEVP, ispolzuemogo v kachestve visoko-i sverkhvisokochastotnikh dielektrikov" ["Stabilization of HDPE used as a high and superhigh-frequency insulator of the island"], Izvestiya NAN ARGRNS, no. 7, pp. 28-35, 2003. [in Ruissian].

[21] P. A. Du Bois, S. Kolling, and W. Fassnacht, "Modelling of safety for crash simulation", Computational Materials Science, vol. 28, pp. 675-683, 2003

[22] Q. C. Pham, F. Vincent, P. Clarysse, P. Croisille, and I. E. Magnin, "A FEM-based deformable model for the 3D segmentation and tracing of the heart in cardiac MRI", in Proc. $2^{\text {nd }}$ International Symposium on Image and Signal Processing and Analysis (ISPA 2001), Pula, Croatia, 2001, pp. 250-254.

[23] E. Bechet, H. Minnebo, N. Moes, and B. Burgardt, "Improved implementation and robustness study of the X-FEM for stress analysis around cracks", International Journal for Numerical Methods in Engineering, vol. 64, no. 8, pp. 1033-1056, 2005.

[24] K. S. Shikhaliyev, "Termodinamika i vzaimnoye raspredeleniye makromolekul v sistemakh khlorkhlorsoderzhashie polimeri" ["Thermodynamics and mutual distribution macromolecules in chlor systems chlorine containing polymers"], in Proc. International Scientific and Practical Conference "WORLD SCIENCE”, Dubai, UAE, vol. 5, no. 4 (20), April, 2017, pp. 37-43. [in Russian].

[25] K. S. Shikhaliyev, and I. G. Movlayev, "Issledovaniye sovmestimosti polimerov, khimicheskikh i drugikh osobennostey ikh smesey", ["The study of the compatibility of polymers, chemical and other features of their mixtures"], in Collection of articles of winners of the 10th International Scientific Practical Conference, Russia, Penza, 2017, pp. 31-35. [in Russian].

[26] K. S. Shixaliyev, I. H. Movlayev, and A. I. Alibeyli, "Receding body resins on the basis of ethylene rubbers", European Science Review, no. 5-6, pp. 97-102, 2017.

[27] K. S. Shikhaliyev, "Kompozitsii i izdeliya na osnove polivinilkhlorida" ["Compositions and products based on polyvinyl chloride"], in Collection of articles of the 10th International Scientific Practical Conference, Penza, Russia, July 25, 2017, pp. 19-25. [in Russian].

[28] K. S. Shikhaliyev, and F. A. Amirov, Issledovaniye protsessa polucheniya pokritiy razlichnogo naznacheniya na osnove modifitsirovannogo polimernymi otkhodami neftyanogo bituma [The study of the process of obtaining coatings for various purposes based on petroleum bitumen modified by polymeric waste], in Proc. International Scientific and Practical Conference "WORLD SCIENCE”, Dubai, UAE, vol. 3, no. 8 (24), August, 2017, pp. 10-12. [in Russian]. 